\title{
Low-penalty up to 16-QAM wavelength conversion in a low loss CMOS compatible spiral waveguide
}

Da Ros, Francesco; Porto da Silva, Edson; Zibar, Darko; Chu, Sai T.; Little, Brent E. ; Morandotti, Roberto; Galili, Michael; Moss, David J. ; Oxenløwe, Leif Katsuo

Published in:

Optical Fiber Communication Conference 2016

Link to article, DOI:

10.1364/OFC.2016.Tu2K.5

Publication date:

2016

Document Version

Peer reviewed version

Link back to DTU Orbit

Citation (APA):

Da Ros, F., Porto da Silva, E., Zibar, D., Chu, S. T., Little, B. E., Morandotti, R., Galili, M., Moss, D. J., \& Oxenløwe, L. K. (2016). Low-penalty up to 16-QAM wavelength conversion in a low loss CMOS compatible spiral waveguide. In Optical Fiber Communication Conference 2016 Optical Society of America (OSA). https://doi.org/10.1364/OFC.2016.Tu2K.5

\section{General rights}

Copyright and moral rights for the publications made accessible in the public portal are retained by the authors and/or other copyright owners and it is a condition of accessing publications that users recognise and abide by the legal requirements associated with these rights.

- Users may download and print one copy of any publication from the public portal for the purpose of private study or research.

- You may not further distribute the material or use it for any profit-making activity or commercial gain

- You may freely distribute the URL identifying the publication in the public portal 


\title{
Low-penalty up to 16-QAM wavelength conversion in a low loss CMOS compatible spiral waveguide
}

\author{
Francesco Da Ros ${ }^{1}$, Edson Porto da Silva ${ }^{1}$, Darko Zibar ${ }^{1}$, \\ Sai T. Chu ${ }^{2}$, Brent E. Little ${ }^{3}$, Roberto Morandotti ${ }^{4}$, \\ Michael Galili ${ }^{1}$, David J. Moss ${ }^{5}$, and Leif K. Oxenløwe ${ }^{1}$ \\ ${ }^{1}$ DTU Fotonik, Technical University of Denmark, DTU, Kongens Lyngby, 2800, Denmark, DK \\ ${ }^{2}$ Department of Physics and Materials Science, City University of Hong Kong \\ ${ }^{3} X i$ 'an Institute of Optics and Precision Mechanics, CAS, Xi'an, China PRC \\ ${ }^{4} I N S R$ - Énergie,Matériaux et Télécommunications, 1650 Blvd Lionel Boulet, Varennes (Québec), J3X1S2, Canada \\ ${ }^{5}$ Schoof of Electrical and Computer Engineering, RMIT University, Melbourne, VIC 3001, Australia \\ fdro@fotonik.dtu.dk
}

\begin{abstract}
Wavelength conversion of 32-Gbaud QPSK and 10-Gbaud 16-QAM is demonstrated using a 50-cm long low loss spiral Hydex-glass waveguide. BER $<$ HD-FEC threshold is achieved over $10 \mathrm{~nm}$ bandwidth with OSNR penalty $<0.5 \mathrm{~dB}$.

OCIS codes: (190.4390) Nonlinear optics, integrated optics; (190.4380) Nonlinear optics, four-wave mixing; (060.1660)

Fiber optics and optical communications, coherent communications.
\end{abstract}

\section{Introduction}

All-optical wavelength conversion is one of the most promising all-optical signal processing techniques which may find applications in future optical wavelength division multiplexed (WDM) networks, in order to provide basic functionalities such as routing in the optical domain [1], as well as more advanced ones such as Kerr nonlinearity mitigation through optical phase conjugation [2].

Transmission systems are steadily migrating towards more advanced modulation formats ranging from quadrature phase-shift keying (QPSK) to 16- quadrature amplitude modulation (QAM), with QPSK systems already commercially deployed. Wavelength converters are therefore required to provide modulation format independent operation that can satisfy the more stringent requirements for optical signal-to-noise ratio and phase noise introduced by this increase in signal complexity. Significant progress has been made for wavelength converters based on fourwave mixing (FWM) in highly nonlinear fibers (HNLFs), with conversion of dual-polarization 64- QAM signals recently being demonstrated [3]. Nonlinear processing in HNLFs is, however, hindered by stimulated Brillouin scattering (SBS). Techniques such as fiber straining [4] or phase dithering in counter-phasing operation [3] have been shown to mitigate the impact of SBS without significant additional penalty; however, they come at the price of increased fabrication or system complexity.

Performing wavelength conversion in a compact waveguide device not only offers the potential benefits of reduced footprint, cost and increased scalability, but has the added benefit of generally having negligible SBS. Wavelength conversion based on integrated devices has been reported for advanced modulation format such as QPSK [5-7], 16- QAM [8, 9], and up to 128-QAM orthogonal frequency division multiplexing (OFDM) [10] using silicon [5,7-10] and silicon-germanium [6] waveguides. However, these materials are well known to be limited by nonlinear absorption at telecom wavelengths, and this has motivated the search for other nonlinear material platforms such as AlGaAs [11], silicon nitride [12] and Hydex [13-15] that exhibit a much higher nonlinear figureof-merit (FOM) [13].

In this paper, FWM-based wavelength conversion of 32-Gbaud QPSK and 10-Gbaud 16-QAM signals in an integrated $50-\mathrm{cm}$ long low loss spiral Hydex waveguide is reported. Continuous-wave $(\mathrm{CW})$ pumping with only moderate pump power $(22 \mathrm{dBm})$ is employed. The negligible nonlinear loss in Hydex near $1550 \mathrm{~nm}$, even at very high pump powers ( $>500 \mathrm{~W}[15])$, leads to an extremely high FOM that, when combined with the low linear loss $(<0.07 \mathrm{~dB} / \mathrm{cm})$, enables attractive FWM performance by allowing the use of long waveguide devices to compensate for the modest Kerr nonlinearity [13]. The signal quality after wavelength conversion is experimentally investigated showing an optical signal-to-noise ratio (OSNR) penalty below $0.5 \mathrm{~dB}$ over a bandwidth of $10 \mathrm{~nm}$. This constitutes the first demonstration of wavelength conversion of continuous data signals in a Hydex waveguide confirming the potential of the Hydex platform for nonlinear optical signal processing. 


\section{Experimental setup}

The experimental setup is shown in Fig. 1. A QPSK or 16-QAM optical signal is generated by modulating a CW external cavity laser (ECL) using a standard IQ modulator driven by a 64 Gsample/s arbitrary waveform generator (AWG) with $20 \mathrm{GHz}$ of analog bandwidth. Another ECL (linewidth $<100 \mathrm{kHz}$ ) at $1551 \mathrm{~nm}$ is used as CW pump for the single-pump FWM scheme. The pump and signal are separately amplified in erbium-doped fiber amplifiers (EDFAs) and the amplified spontaneous emission noise (ASE) is filtered out by optical band-pass filters (OBPFs) with a full-width half-maximum (FWHM) bandwidth of $0.8 \mathrm{~nm}$ and $0.5 \mathrm{~nm}$ for signal and pump, respectively. The two waves are then coupled together into the Hydex spiral waveguide with their states-of-polarization aligned to maximize the conversion efficiency (CE) by the use of polarization controllers (PCs). The spiral waveguide has a cross section of $1.45 \mu \mathrm{m} \times 1.50 \mu \mathrm{m}$ (Fig. 1(a)), surrounded by a silica cladding [13].

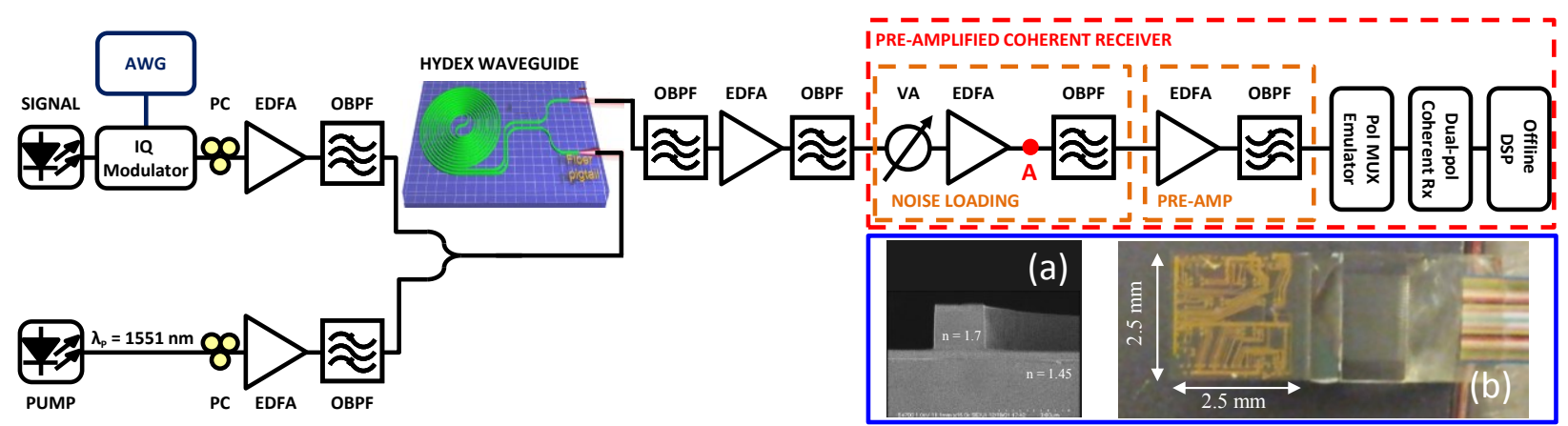

Fig. 1. Experimental setup: point A highlights the measurement point for the received OSNR. Inset: (a) scanning electron microscope (SEM) image of the waveguide cross-section prior to glass deposition and (b) picture of the waveguide complete with the fiber pigtails.

The total insertion loss, including propagation loss, mode converter loss and pigtail splicing loss is $10.5 \mathrm{~dB}$. The group velocity dispersion is anomalous at $-10 \mathrm{ps}^{2} / \mathrm{km}$ at $1550 \mathrm{~nm}$ and the nonlinear parameter $\gamma$ is $220 \mathrm{~W}^{-1} \cdot \mathrm{km}^{-1}[13]$. The lower nonlinear parameter compared to silicon is compensated for by the significantly lower propagation losses leading to a longer effective length as well as the ability to use larger pump powers without any impact from nonlinear losses [15]. This demonstration, however, could be performed using moderate pump (22 $\mathrm{dBm})$ and signal $(16.5 \mathrm{dBm})$ powers. The spectra at the output of the waveguide for a signal wavelength of $1549 \mathrm{~nm}, 1546 \mathrm{~nm}$ and $1541 \mathrm{~nm}$ are shown in Fig. 2.
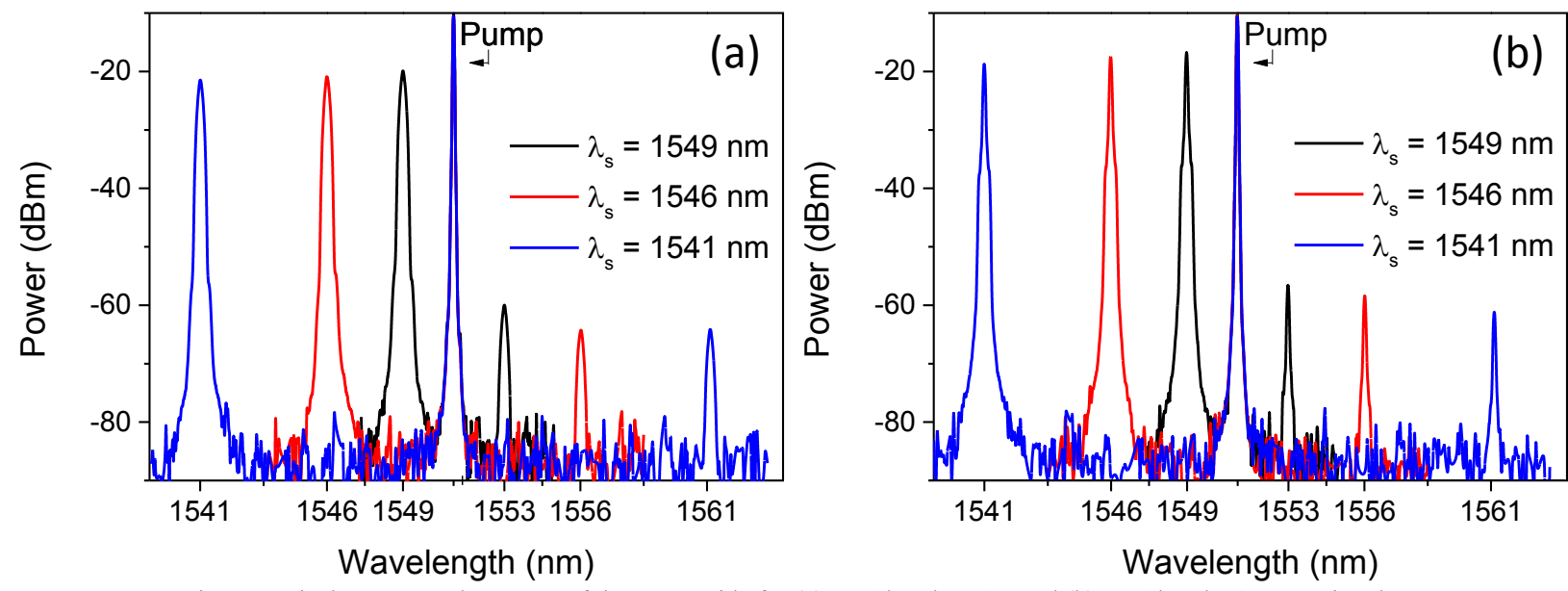

Fig. 2. Optical spectra at the output of the waveguide for (a) 32-Gbaud QPSK and (b) 10-Gbaud 16-QAM signals.

The $\mathrm{CE}$ is around $-40 \mathrm{~dB},-41 \mathrm{~dB}$ and $-42.5 \mathrm{~dB}$ for the three signal wavelengths, respectively. These values can be increased by using higher pump power since quadratic scaling has already been shown [14]. However, in this demonstration the available idler OSNR was already sufficient for demodulating the data. After the waveguide, the idler was selected with a 2-nm wide OBPF, pre-amplified and filtered again with a 1-nm wide OBPF to fully suppress pump and signal. The idler quality was then evaluated using a standard pre-amplified coherent receiver consisting of a noise loading stage, a pre-amplification stage, and a dual-polarization coherent receiver. A polarization emulator was used to generate a dual-polarization signal compatible with our receiver configuration. 
The received waveforms from the digital sampling oscilloscope (DSO, 80 Gsamples/s, $33 \mathrm{GHz}$ ) were processed by offline digital signal processing (DSP) [16] including adaptive time-domain equalization using constant and multimodulus algorithms, carrier recovery by decision-directed phase lock loop and error vector magnitude (EVM) measurements followed by bit error rate (BER) estimation based on the EVM [17].

\section{Results and discussion}

The performance of the integrated wavelength converter was first tested with a 32-Gbaud QPSK signal for a signal-pump spacing of $2 \mathrm{~nm}, 5 \mathrm{~nm}$ and $10 \mathrm{~nm}$. The estimated BER of the wavelength converted idler is shown as a function of the signal OSNR at the receiver (measured at point A in Fig. 1) in Fig. 3 (a) and benchmarked with the back-to-back signal performance measured directly at the output of the IQ modulator.

The comparison shows that all the curves are within $<0.7 \mathrm{~dB}$ OSNR difference throughout the measured range. Changing the spacing from $2 \mathrm{~nm}$ to $10 \mathrm{~nm}$ caused a $3 \mathrm{~dB}$ reduction in received OSNR. This behavior follows directly from the decrease in CE. Nevertheless all the idlers reached a BER below the hard decision forward error correction (HD-FEC) threshold ( $\mathrm{BER}=3.8 \times 10^{-3}$ ) with less than $0.5 \mathrm{~dB}$ OSNR penalty compared to back-to-back.
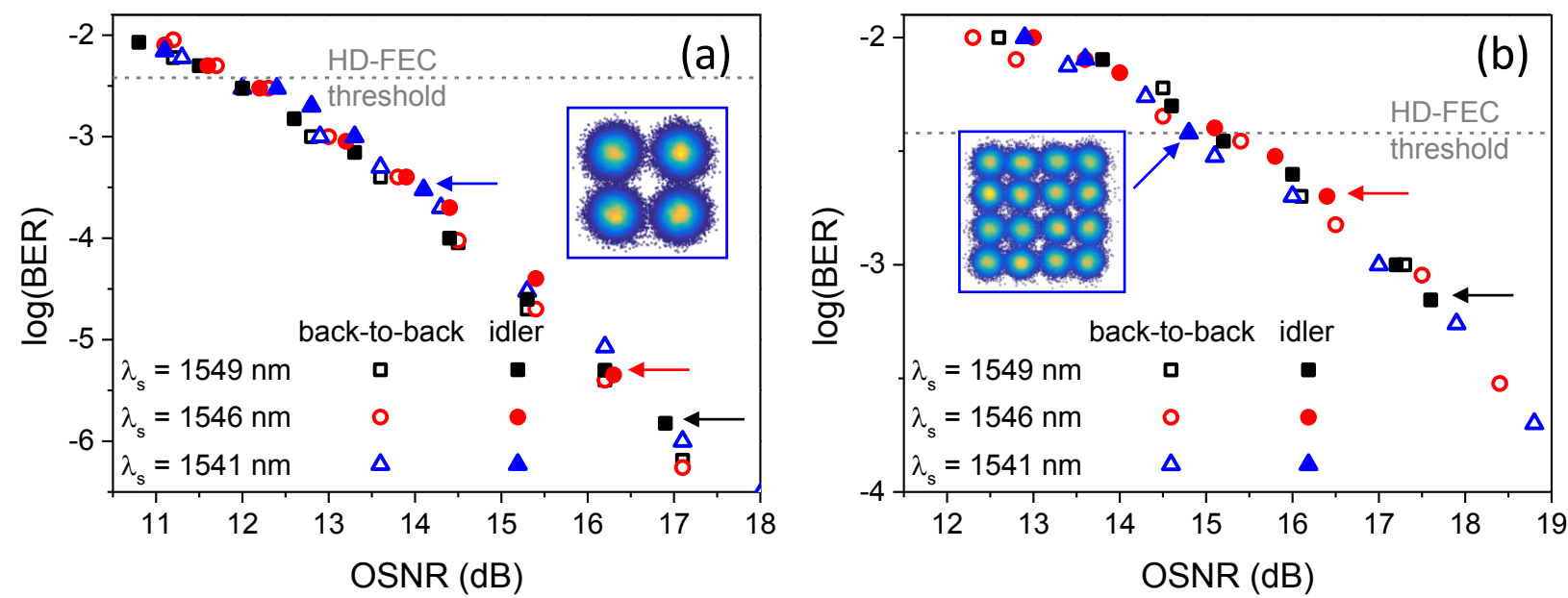

Fig. 3. BER performances as a function of the received OSNR (point A in Fig. 1) for (a) 32-Gbaud QPSK signals and (b) 10-Gbaud 16-QAM signals: comparison between back-to-back signal (open) and wavelength converted idler (full). Arrows point at the maximum receiver OSNR after wavelength conversion and the inset constellation diagrams refer to the idler at $1561 \mathrm{~nm}$ for maximum received OSNR.

Fig. 3 (b) shows similar results for a 10-Gbaud 16-QAM signal. The OSNR penalty is still less than $0.5 \mathrm{~dB}$ at the HD-FEC threshold. All three idlers could be received with BER better than the HD-FEC limit even though in this scenario the constraints on the available OSNR due to the limited CE were more stringent allowing only a minimum BER slightly below the HD-FEC threshold for 10-nm signal-pump spacing, even while decreasing the symbol rate. However, we believe that this is not a fundamental limitation since the negligible nonlinear loss [15] would allow the use of higher pump powers or longer waveguides, leading to a higher CE and thus a higher idler OSNR.

\section{Conclusion}

We demonstrate wavelength conversion of 32-Gbaud QPSK and 10-Gbaud 16-QAM using a spiral Hydex waveguide under $\mathrm{CW}$ pumping operation. The performance was investigated by varying the signal-pump separation by up to $10 \mathrm{~nm}$. In all cases, BER below the HD-FEC threshold was achieved with OSNR penalties below $0.5 \mathrm{~dB}$, compared to back-to-back.

\section{Acknowledgments}

This work was supported by the Center of Excellence Silicon Photonics for Optical Communications (SPOC) funded by the Danish National Research Foundation, by the National Science and Engineering Research Council in Canada, and by the Australian Research Council (ARC) discovery projects program.

\section{References}

[1] S. Yan, et al., J. Lightw. Technol. 33, 1586-1595 (2015).

[2] A. Yariv, et al., Opt. Lett. 4, 52-54 (1979).

[3] H. Nguyen Tan, et al. ECOC 2015, paper We.2.6.1.

[4] B.P.-P. Kuo, et al., Opt. Expr. 20, 18611-18619 (2012).

[5] D. Vukovic, et al., Opt. Expr. 23, 3640-3646 (2015).

[6] M.A. Ettabib, et al., Opt. Expr. 21, 16683-16689 (2013).

[7] X. Wang, et al., Opt. Lett. 39, 6122-6125 (2014).

[8] R. Adams, et al., Opt. Expr. 22, 4083-4090 (2014).

[9] X. Wang, et al., POEM 2015, paper OW2A.5.
[10] C. Li, et al., Opt. Lett. 39, 4583-4586 (2014).

[11] M. Pu, et al., OFC 2015, paper Th5A.3.

[12] C.J. Krückel, et al., Opt. Lett. 40, 875-878 (2015).

[13] D.J. Moss, et al., Nat. Phot. 7, 597-607 (2013).

[14] D.M. Ferrera, et al., Nat. Phot. 2, 737-740 (2008).

[15] D. Duchesne, et al., Opt. Expr. 17, 1865-1870 (2009).

[16] R. Borkowski, et al., IEICE Trans. Comm.. 97, 1528-1536 (2014).

[17] R. Schmogrow, et al., Phot. Tech. Lett. 24, 61-63 (2012). 